\title{
O tema da razão em Horkheimer e Schopenhauer
}

\author{
The theme of reason for Horkheimer and Schopenhauer
}

\author{
Maria Lúcia Cacciola \\ mcacciola@uol.com.br \\ (Universidade de São Paulo, São Paulo, Brasil)
}

\begin{abstract}
Resumo: Trata-se de buscar as afinidades entre o pensamento de Max Horkheimer e Arthur Schopenhauer, tendo como fio condutor o conceito de razão, tal como se apresenta em ambos. Neste percurso buscamos mostrar as diferenças de leitura da filosofia schopenhaueriana, sobretudo no que tange ao seu propalado conservadorismo, destacando a originalidade e perspicácia da leitura de Horkheimer, que deu origem a uma "esquerda schopenhaueriana". O intuito é também o de repensar o sentido do conceito de sistematicidade racional e de sua crítica por Schopenhauer e Horkheimer.
\end{abstract}

Palavras-chave: filosofia crítica; razão; sistema; representação; negatividade.

\begin{abstract}
This article investigates the affinities between Max Horkheimer's thought and Arthur Schopenhauer's, taking as a guiding thread the concept of reason, as presented by both. In doing so, we will try to point to the different interpretations of the Schopenhauerian philosophy, especially concerning his proclaimed conservatism, emphasizing the originality and the perspicacity of Horkheimer's interpretation, which originated a "Schopenhauerian left". Our goal is also to rethink the meaning of the concept of rational systematicity and its critique by Schopenhauer and Horkheimer.
\end{abstract}

Keywords: critical philosophy; reason; system; representation; negativity.

Nessa busca das afinidades entre Schopenhauer e Horkheimer, nos ateremos principalmente ao conceito de Razão, tal como exposto por Schopenhauer no Mundo como Vontade e Representação e nos Parerga e Paralipomena e por Horkheimer nos escritos Meios e Fins, Juliette [ $2^{\circ}$ excurso da Dialética do esclarecimento] e a Atualidade de Schopenhauer.

Como se sabe, Horkheimer começou seu estudo de Filosofia com Schopenhauer e ao que parece nunca se afastou por completo do espírito de sua filosofia (Chiarello 2004, especialmente pp.23,67). ${ }^{1}$ Schopenhauer, visto como um filósofo conservador por muitos de seus leitores, como, por exemplo, Lukács (1975) na Destruição da razão ${ }^{2}$ e Paulo Arantes (1996, p.56, nota 88) no Ressentimento da dialética, um

1 Chiarello, ao mostrar a presença de Schopenhauer desde as primeiras obras dos anos 1920 e 1930, pretende assinalar a continuidade na obra de Horkheimer, afastando-se dos comentadores como Habermas que vêm um profundo corte entre a primeira filosofia do autor e a sua filosofia posterior, a partir dos anos 1940, quando se radicaliza a crítica da Razão. Cf. Chiarello 2004, pp.20-22.

2 Título em alemão: Die Zerstörung der Vernunft. 
verdadeiro marco do pensamento reacionário, em virtude não só de suas visadas políticas, mas do caráter apologético da sociedade burguesa e conservadora, é, em contrapartida, visto por Horkheimer como um verdadeiro libelo contra o status quo (Horkheimer, 1986).

\section{Crítica à razão}

A crítica à razão do Esclarecimento será o tema central e fio condutor do nosso estudo sobre o parentesco entre os dois autores, assumido direta e indiretamente por Horkheimer.

A crítica de Horkheimer à razão instrumental a contrapõe a uma razão objetiva que teria sido dominante nas metafísicas passadas. É notável que esta razão de caráter subjetivo, tal como descrita por Horkheimer, reproduz o conceito de razão em Schopenhauer (Horkheimer, 1973, pp.15ss; Schopenhauer 2005b; Schopenhauer, 1980b). Ou seja, a razão criticada por Horkheimer como um produto subalterno de uma determinada organização social é em Schopenhauer a verdadeira e única definição de razão. Parece então paradoxal buscarmos a proximidade dos dois por meio do conceito de razão. A razão instrumental é uma razão empobrecida, reduzida a calcular os meios para certos fins, esquecida de qualquer visão especulativa e reduzida a um instrumento de sobrevivência (Horkheimer, 1973, pp.15ss). Em Schopenhauer, a razão é uma função do aparato cognitivo, produtora de representações abstratas e a quem cabe a função lógica. É a razão de conhecer, uma das modalidades do princípio de razão (as demais são o princípio de razão do devir, o do ser e o do querer). Eminentemente formalista, a razão presente na teoria de conhecimento de Schopenhauer, e que é exposta no primeiro livro do Mundo... (Schopenhauer 2005a, pp.47ss.), não se distingue a nosso ver da razão instrumental tão criticada por Horkheimer. Se nos ativermos ao conceito de razão em Schopenhauer podemos afirmar sem hesitação que não há entre os dois filósofos qualquer afinidade nesta apreciação da razão, apenas uma relação de crítica ou conflito, pois se Horkheimer propõe uma razão objetiva que teria sofrido uma redução ao se transmutar numa razão subjetiva ou instrumental, Schopenhauer descreve a razão no primeiro livro do mundo como uma razão subjetiva, função da mente que rege tão só as representações abstratas (idem, ibidem; e ainda Schopenhauer, 1988, §34).

Vale, no entanto, lembrar o que significa no contexto da filosofia de Schopenhauer este conceito de razão; qual a sua relevância e qual o seu alcance ao nível do saber. 0 mundo e o saber filosófico sobre o mundo não se esgotam para Schopenhauer no ponto de vista da representação, mas exigem seu pendant, o Mundo como Vontade, o lado propriamente metafísico. É justamente pela pobreza deste significado do mundo como Representação que é preciso investigar seu outro lado, a Vontade. "O mundo 
é minha vontade é uma verdade que tem de ser deveras séria e grave para cada um, quando não terrível" (Schopenhauer, 2005a, pp.44-45). ${ }^{3}$ Segundo o Filósofo, o nome é tomado de empréstimo do âmbito das representações, mas não de modo arbitrário; o querer empresta esse nome do fenômeno que melhor a expressa e que é a vontade humana, sempre em busca de sua própria conservação, o querer viver (idem, p.169). Com isso, Schopenhauer encontra a essência do mundo no próprio mundo e não além dele, professando, como ele próprio diz, uma metafísica “imanente” ou nas palavras do filósofo: "meu sistema poderia ser chamado de dogmatismo imanente, pois, embora seus princípios doutrinais sejam de fato dogmáticos, não ultrapassam todavia o mundo dado na experiência, mas apenas esclarecem o que ele é, já que o decompõe em suas partes" (Schopenhauer, 2003, p.118). ${ }^{4}$ Visando o querer viver como outro lado do mundo, sua explicação última, Schopenhauer afasta a concepção de uma inteligência última ou razão divina como sendo a fonte de significado do mundo. É esse impulso cego, a vontade, que impulsiona as ações do homem e dos demais seres, como a essência comum a todos.

Esse querer viver como impulso de conservação e móvel das ações humanas é tomado por modelo da "razão instrumental" em Horkheimer. No entanto, como vimos, para Schopenhauer, este querer é um impulso ou ímpeto e não tem qualquer caráter racional, pois a racionalidade só se encontra fechada no mundo visto como representação. Para chegar a algo que seria uma "razão subjetiva" é necessário que essa Vontade ou querer viver seja representada abstratamente, em conceitos, já que, para Schopenhauer, o intelecto é um produto do organismo e este da Vontade. Parece claro ver na própria razão de conhecer schopenhaueriana o modelo pronto de razão subjetiva ou instrumental, descrito por Horkheimer. Se Horkheimer alega a precedência de uma razão objetiva, esta nem aparece na filosofia de Schopenhauer, o que não quer dizer que na sua filosofia haja qualquer pretensão de que a razão representativa esgote o conhecimento do Mundo. Apesar das importantes funções desta mesma razão, entre as quais a "comunicabilidade", que permite transmitir conhecimentos pela linguagem, que possibilita a ciência e a vida em comum dos homens, em suma sua organização em sociedades, ela é meramente operacional (Schopenhauer, 2005a, p.105).

Mas para Schopenhauer, o conhecimento não se esgota no âmbito da representação e do princípio do conhecer, cuja função atuante é a razão. Esse tipo de conhecimento nos dá apenas a relação entre os fenômenos ou “objetos”, deixando de

\footnotetext{
3 No primeiro capítulo de sua obra, Schopenhauer menciona a dificuldade que temos em aceitar que o mundo seja apenas representação, mera aparência, sem um significado que expresse sua realidade. Por isso é preciso buscar seu outro lado, a verdade dificilmente alcançada de que ele tem uma essência, à qual Schopenhauer nomeia Vontade.

4 Também na "Crítica à filosofia kantiana", Schopenhauer menciona o esquecimento da experiência como única fonte da metafísica e o engano de se pensar a metafísica como algo para além da física. Ver Schopenhauer, 1980b, p.95.
} 
lado a realidade do mundo, ou melhor, a sua objetividade. A crítica que Schopenhauer faz ao conhecimento abstrato, que se afasta do intuitivo (Schopenhauer, 1980b, p.103), o impede de conferir à razão, tal como ele a pensa e que só opera com conceitos abstratos, o poder de chegar a uma verdade mais do que formal. Daí a sua crítica a Kant, por ter este se valido da abstração para apresentar um conhecimento objetivo e, ainda mais, para fundamentar uma moral. A razão como conhecimento abstrato não poderia para o filósofo de Dantzig nem "ter como essência a exigência de um incondicionado" (idem, p.140), nem o poder de produzir Ideias no campo teórico e muito menos de estabelecer uma legislação moral eficaz, que agisse sobre o comportamento humano, que em sua origem na força vontade de viver e no caráter formado por ela (idem, pp.173ss).

O conhecimento verdadeiro e objetivo para Schopenhauer, o conhecimento do em si do mundo, deve ser buscado em outro campo que não o conhecimento quotidiano ou das ciências positivas, no sentimento dado a cada um do próprio corpo, como atividade e não mais como mera representação, pois o filósofo não é apenas o sujeito que conhece [cabeça de anjo alada, destituída de um corpo] (Schopenhauer, 2005a, p.156; original alemão: Schopenhauer, 1911, p.119). A essência verdadeira de cada um é dada por meio das ações do corpo, ações que são o mesmo que os atos da vontade, já que o corpo é sua primeira objetivação (Schopenhauer, 2005a, p.157; Schopenhauer, 1911, p.119). Por sua vez o conhecimento objetivo é dado na Metafísica do Belo, e assim por meio da arte e do belo natural, pois embora se apresentem como representações, escapam das modalidades do princípio de razão, levando até mesmo a uma espécie de curto-circuito da representação, que se dá quando, na contemplação estética, é desfeita a polaridade sujeito e objeto - própria à representação -, que se fundem e passam a coincidir na Ideia, como "objetidade [Objektität] adequada da vontade" (Schopenhauer, 2005a, p.248; Schopenhauer, 1911, p.211).

Vemos assim que o conceito de razão schopenhaueriana, tal como exposto na Quadrupla raiz e no primeiro livro do mundo, é por demais estreito para abarcar o que Horkheimer chama de razão objetiva, mas a expressão desta na filosofia de Schopenhauer, por extrapolar a relação causal que explica o devir e a razão de conhecer que liga as representações abstratas, é alargada para os demais âmbitos do saber, como a arte e a moral, onde vige o sentimento de compaixão, fundado metafisicamente na mesma essência de cada um, a Vontade. ${ }^{5}$ [Frisemos por outro lado que o Horkheimer da época da Filosofia crítica e tradicional concebe esse alargamento como irracional]. Mas, mesmo posta esta diferença das respectivas

\footnotetext{
5 Mauricio Chiarello (2004, p.96 e nota 26) comenta a radicalidade da posição de Horkheimer em "Razão e autoconservação" (Vernunft und Selbsterhaltung) que se ameniza dois anos depois no Eclipse da Razão (Eclipse of Reason) onde ele admite uma razão objetiva.
} 
concepções de razão, ambos fazem a crítica da Razão do Esclarecimento, tendo como alvo principal a filosofia kantiana.

\section{Dialética do esclarecimento}

No excurso II, "Juliette ou o esclarecimento e a Moral", cita Horkheimer a definição de Esclarecimento dada por Kant na resposta à pergunta "O que é o Esclarecimento": "a saída da menoridade auto inculpável”, ou seja, "o uso que se faz de seu próprio entendimento sem a direção de outros" (Kant, 1900b, p.35, apud Adorno e Horkheimer, 1985, p.81). ${ }^{6}$ Para Horkheimer, Kant quer com isso dizer que o entendimento sem direção de outros é aquele que é dirigido pela razão. Pois ela é que reúne os conhecimentos isolados num sistema, unificando os conhecimentos isolados do entendimento, sendo que tal sistema tem de derivar de um princípio único (Adorno e Horkheimer, 1985, p.81). Sem discutir aqui essa interpretação rigorista que pode bem referir-se à leitura pós-kantiana, frisemos que a crítica de Horkheimer parte desta assumpção que ele vê expressa na Crítica da razão pura: "a razão tem por único objeto o entendimento e sua aplicação funcional” (Kant, 1900a, p.427, apud Adorno e Horkheimer, 1985, p.81).

O pensamento que se produz no Esclarecimento é a conexão dos conhecimentos numa ordem científica unitária, dando-the o aspecto unitário. Todo o conhecimento deriva de princípios: sejam abstrações, axiomas, ideias inatas. 0 pensamento factual deriva do princípio (Adorno e Horkheimer, 1985, p.81).

A própria percepção subjetiva é intelectualizada, pois, "o esquematismo do entendimento puro homogeneíza o particular e o universal” (Adorno e Horkheimer, 1985, p.82). A inteligibilidade, a saber, a objetividade é impressa na coisa antes mesmo que seja percebida. O fio condutor para organizar a experiência é a concordância a priori da natureza com o nosso juízo unificador. No Esclarecimento, "as contradições se escondem por traz da clareza e uniformidade de seus juízos". Assim temos segundo Horkheimer a unidade do sujeito transcendental que unifica a todos, numa "utopia da liberdade", e, ao mesmo tempo essa mesma razão como poder calculador que se rege pelo fim de autoconservação, subjugando e transformando o material dos sentidos em prol da constituição da ciência atual como "interesse da sociedade industrial" (idem, p.83). Por trás dessa falsa harmonia entre o universal e o particular estaria o esquematismo atuando como um elemento de dominação. Tudo, indivíduos e animais são peças a serem repostas de acordo com os modelos do sistema. "Os sentidos já

\footnotetext{
6 As citações de Kant provêm, como esclarece o próprio autor na nota 1 do excurso (idem, p.249), do artigo "Beantwortung der Frage: Was ist Aufklärung" (Resposta à pergunta: O que é a Ilustração). Neste artigo, publicado no Mensário berlinense, Kant é incitado a definir Esclarecimento, a partir de uma polêmica suscitada no âmbito da esfera deste conceito e que chega a acusá-lo de subversivo por querer imiscuir-se em questões de religião.
} 
estão condicionados pelo aparelho conceitual e antes que a percepção ocorra, o cidadão vê a priori o mundo como a matéria com a qual ele o produz para si próprio" (idem, ibidem).

O conhecimento consiste na subsunção a princípios e coincide com o juízo que se insere no sistema. A razão fornece a ideia da unidade sistemática. 0 desrespeito ao sistema traz como consequência a morte, pois o sistema que funda as ciências é para os autores o modo mais eficaz de lidar com a natureza e sua dominação. 0 menor é aquele que não é capaz de usar seu entendimento e portanto de se conservar vivo. 0 sujeito lógico do Esclarecimento é o burguês nas suas figuras diversas: o dono de escravos, o empresário, o administrador. Quando a razão se torna hegemônica, separando-se da vida e do sentimento transforma-se em desrazão. Se o sentimento e suas manifestações como a religião e a arte são isolados e deixam de fazer parte do conhecimento, a "razão pura" os expulsa do comprometimento com o pensamento e eles são elementos neutralizados dessa razão do sistema econômico capitalista e de seu irracionalismo inerente (Adorno e Horkheimer, 1985, p.90).

\section{Crítica de Schopenhauer ao sistema e à abstração em Kant}

0 traço de proximidade entre a crítica à filosofia kantiana nos dois textos, a Dialética do esclarecimento de Adorno e Horkheimer e a "Crítica da filosofia kantiana" de Schopenhauer tem como centro a noção de sistema. A razão, enquanto fornecedora da unidade sistemática, é o alvo privilegiado de ambos. Já na Crítica à Analítica configura-se a crítica à noção de sistema, censurados por Schopenhauer tanto o "amor pela simetria" como o espírito sistemático de Kant, que teriam feito com que ele, na Analítica, buscasse um pendant para as intuições puras a priori do tempo e do espaço na Estética, adotando os conceitos puros a priori, as categorias, para dar conta da objetividade do conhecimento (Schopenhauer, 1980b, p.112). Mas Schopenhauer nunca dará a chancela de objetivo a esse conhecimento da natureza assim obtido, pois a sua crítica, apesar de ser metodológica, não fica por aí. A condenação à abstração como resultado do processo de "coligir a diversidade fenomênica em conceitos abstratos" (idem, p.116) tem um sentido mais profundo de abarcar o conteúdo desse saber, que abstrai o conteúdo dos conceitos, ficando com a "sombra dos objetos", ao perder a referência ao intuitivo (idem, pp.11617). Assim para Schopenhauer a ideia de uma racionalidade prévia, que regulasse por meio de princípios a observação dos fenômenos, é descartada como quimérica e deturpadora do "real". A especificidade do mundo fenomênico se perde numa abstração totalizadora. Talvez seja o caso de se contrapor a gênese dessa crítica à totalização e à sistematicidade em Schopenhauer à de Horkheimer, lembrando que a crítica à razão e ao espírito sistemático tem, no primeiro, um certo tom ainda 
Aufklärer, pois pretende pôr empecilhos a construções dogmáticas, a sistemas tais como os da metafísica clássica a quem Kant teria deixado, segundo ele, abertas as portas do fundo de sua filosofia, ao considerar como uma e a mesma razão, a razão prática e a razão teórica (Schopenhauer, 1995, pp.25-27, 47). Nesta direção até mesmo o uso regulativo das ideias transcendentais, considerado imprescindível por Kant, e que "consiste em dirigir o entendimento para um determinado objetivo, com vistas ao qual as linhas de orientação de todas as suas regras se dirigem para um único ponto" (Kant apud Cacciola, 1983, p.100) é censurado por Schopenhauer. As ideias transcendentais "ao invés de propiciarem avanço nas ciências seriam forte entrave para suas descobertas", por afastar a razão, ao conferir-lhe unidade sistemática, da sua fonte verdadeira, o mundo imediato e intuitivo (cf. Cacciola, 1983, p.101; Schopenhauer, 1980b, p.165). A razão não precisa, para criticar o conhecimento por ela obtido, nada mais do que "investigar a referência do abstrato e do intuitivo" e impedir que se tornem esferas incomensuráveis (cf. Cacciola, 1983, p.101; Schopenhauer, 1980b, p.140).

O sistema kantiano, suas divisões e subdivisões, enfim o gosto pela simetria, vai fornecer a estrutura de crítica a Kant e ao desempenho da faculdade de julgar. O filósofo Schopenhauer denuncia em Kant a ausência de "simplicidade, naivität, ingenuité, candeur", afirmando que sua filosofia não evoca a grandeza e harmonia de proporções da arquitetura grega e românica, mas lembra a arquitetura gótica. “Pois uma peculiaridade bem individual do espírito de Kant é o gosto singular pela simetria, que ama a multiplicidade variegada para ordená-la e para repetir a ordenação, em subordinações e assim por diante, como nas igrejas góticas" (Schopenhauer, 1980b, p.97). Schopenhauer evoca a imagem da hierarquia em obediência a um primeiro princípio, a um Deus, ou ser supremo, de onde parte ou onde chega a dedução.

A gênese da crítica ao abstrato em Horkheimer parece ser bem diversa, embora em seus termos ambas pareçam semelhantes, por exemplo, na crítica à pretensão de objetividade do conhecimento de uma mera razão subjetiva, mera hibris desta forma de razão. Por exemplo, na Dialética do esclarecimento o que foi deixado de lado mais diretamente para Horkheimer, não são as meras representações, ainda subjetivas, mas são as condições materiais de existência que estariam na base de uma abstração, tal como a unidade sintética da apercepção como ponto supremo que pretenderia ligar a lógica inteira (Adorno e Horkheimer, 1985, p.96). Na concepção de Horkheimer, é a autoconservação e a visão antecipadora dos indivíduos, acompanhada da reflexão que dá o conjunto, o que estrutura e funda o conhecimento científico. Citando: "ao longo das gerações, o ego se expande e se contrai com as perspectivas da autonomia econômica e da propriedade produtiva, sendo a instância da visão antecipadora e da visão de conjunto reflexionante" (idem, ibidem).

Fica claro aqui que o papel da razão, sendo meramente formal, está à disposição 
de todo e qualquer interesse natural. "O pensamento é um simples órgão, uma função da mente e passa a fazer parte da natureza". Se no liberalismo os burgueses se controlam uns aos outros na competição, no fascismo vige o terror da dominação. Os homens tornam-se matéria manipulável.

No entanto essa ênfase na autoconservação, na dominação e na transformação dos homens e coisas aproxima ambos os filósofos de maneira irrecusável, embora em Horkheimer prevaleça o ciclo de dominação, ao enfatizar o tempo e a história. A crítica ao sistema e ao caráter sistemático da filosofia de Kant persiste em Horkheimer quando ele aponta nela "a fundamentação transcendental da afinidade entre o conhecimento e o plano, rebatida no caráter de uma inescapável funcionalidade da vida burguesa integralmente racionalizada" (Adorno e Horkheimer, 1985, p.87), mesmo no lazer. Para Horkheimer, é em Sade que se expõe a fúria sanguinária que vem do cálculo, sem qualquer disciplina, sob o império da dominação. "A obra do Marquês de Sade mostra o 'entendimento sem a direção de outrem', ideal do esclarecimento como sendo o burguês liberto de toda tutela" (idem, p.85). Citemos:

As equipes desportivas modernas, cuja cooperação está regulada de tal modo que nenhum membro tenha dúvida sobre seu papel e para cada um haja um suplente a postos, encontram seu modelo exato nos times sexuais de Juliette, onde não há ócio em nenhum instante e onde nenhuma abertura do corpo é desdenhada. No esporte e na cultura de massa reina uma atividade totalmente funcional (idem, p.87).

E por fim lembrando a menção à arquitetura feita por Schopenhauer, ao comparar o sistema kantiano à catedral gótica com suas divisões e subdivisões, contrapondo-a à singeleza românica; Horkheimer evoca "a estrutura arquitetônica própria do sistema de Kant" comparando-a "às pirâmides de ginastas das orgias de Sade, e os princípios das lojas maçônicas burguesas". 0 afã na organização teria se mostrado também em outras épocas sem mitologia, "pesando o esquema da atividade mais do que o seu conteúdo" (idem, ibidem).

E se Horkheimer ou até mesmo Schopenhauer, o Kaspar Hauser da filosofia segundo seu discípulo Dorguth (Schopenhauer, 2003, p.124), tivessem conhecido Macunaíma, o herói do "cada um por si e Deus contra todos", cujas peripécias eram regidas pelo acaso em busca do Muiraquitã, o amuleto da sorte, talvez vissem nele e na preguiça que o movia e o demovia a contraposição ao totalitarismo da ordem burguesa e da sociedade administrada (Andrade, 2016). Na cena do filme inspirado na obra de Mário de Andrade, ${ }^{7}$ locada na piscina borbulhante de feijoada, no palacete burguês do parque Lage, Macunaíma, nas suas estripulias sem qualquer previsão e sentido, a não ser a busca de um ícone místico, num malabarismo estrambótico, agarrado num cipó, vence com astúcia o ricaço poderoso que acaba afogado e queimado ou na macarronada, no livro do paulista Mário, ou na feijoada, na versão

7 Joaquim Pedro de Andrade, Macunaíma (1969, 110', Brasil), baseado no livro de Mário de Andrade. 
fílmica do carioca Joaquim Pedro de Andrade. Se Macunaíma sobrevive ou "vinga", como se diz popularmente, é obra do acaso e da esperteza. Embora no final do livro o herói indolente e enfastiado lamente a falta de sentido da sua vida, necessário até para tomar um rumo até a ilha de Marajó, se conforma com sua nulidade e vazies, e dela se despede heroicamente, transformando-se em constelação (Andrade, 2016, p.121). Talvez um confronto entre uma cultura mítica, figurada por Macunaíma e sua tribo indígena, e a sociedade administrada que daria um fim ao que resta de uma cultura não massificada. A verdadeira causa da exploração e da pobreza, o monstro comedor de homens, o capitalista Venceslau Pietro Pietra, é mascarada na sociedade organizada, pondo-se a culpa da miséria nas saúvas que estariam acabando com o Brasil. Depois dessa digressão pela crítica de Mário, seja ao Brasil atrasado e mítico, seja à locomotiva bandeirante que com sua racionalização puxa os demais vagões, e que, com seus monstros mecânicos e gigantes capitalistas nada melhora, voltemos aos inconformados filósofos, onde vige também a já famosa epígrafe "cada um por si e Deus contra todos". ${ }^{8}$

Em Schopenhauer, o intelecto é sempre dominado pelo querer viver sem telos, mero subproduto do organismo que corporifica o querer. Há um plano que nos é oculto, que mantém a vida, mas cujo desfecho é a morte do indivíduo, justificada pela sobrevivência da espécie. Poderíamos fazer uma analogia entre o querer viver e a razão instrumental de Horkheimer, que se reproduz na sociedade burguesa. Mas para Schopenhauer esse ímpeto do querer viver é essencial, não sofrendo imposições de uma ordem econômica determinada, estando não só biológica mas metafisicamente sempre presente. 0 mal-estar ou a doença da razão não seria reflexo dos tempos e da ordem econômica burguesa ou totalitária, mas esta seria uma das manifestações da essência humana. Se há escapatória? A rigor, não, embora a compaixão, metafisicamente fundada, seja a única que possa alterar os lances do jogo (Schopenhauer, 2005a, Livro quarto, pp.351-518). Porém nada podemos esperar com certeza. Daí o pior dos mundos possíveis e, como única saída, a sua negação (idem, ibidem). A este respeito poderíamos recorrer ao comentador e filósofo contemporâneo, seguidor de Horkheimer, Ludger Lütkeaus, na leitura que faz de Schopenhauer, perguntando com ele "se o pessimismo é um quietismo", e se há uma esquerda schopenhaueriana (Lütkehaus, 2007, pp.15-34). Schopenhauer apesar da sua política conservadora teria algo a opor à injustiça e ao status quo? Logo vem à tona o estado de compaixão, involuntário, mas subversivo do egoísmo próprio aos seres vivos. Mas a atitude compassiva não é uma decisão, podendo ou não se dar, é exceção que confirma a regra, embora seja algo real, empiricamente constatável, o que traz um consolo e joga a favor de uma união entre os seres (Schopenhauer, 1995,

8 Frase de Macunaíma no livro de Mário que inspirou o título original do filme $O$ enigma de Kaspar Hauser, Jeder für sich uns Gott gegen alle (1975, 110', Alemanha Ocidental) de Werner Herzog. 
\$17, p.135). Lütkeaus distingue uma direita e uma esquerda schopenhauerianas. $\mathrm{Na}$ primeira, nomeia Hartmann, e na segunda, como principal representante Horkheimer, seguido de A. Schmidt, Marcuse e Maus. No texto: É o pessimismo um quietismo? vê com Horkheimer na ontologia negativa de Schopenhauer uma ontologia crítica que censura o status quo político e social (Lütkehaus, 2007, pp.16-17), combatendo assim a interpretação lukacsiana que classifica Schopenhauer, ao contrário, como um defensor do status quo e um apologista da burguesia (idem, p.22). Essa leitura, segundo ele, seria bastante superficial, deixando de constatar aspectos importantes, principalmente o inconformismo schopenhaueriano, que

de considerações mais abrangentes sobre o mal do mundo e a dor da existência dirigida por uma vontade cega, envereda para a crítica pontual de fatos empíricos, tais como a escravidão dos negros, as condições das prisões, os males que resultaram de uma sociedade administrada e da técnica que não teria cumprido suas promessas de melhorar a vida (idem, pp.24-25),

dando aos homens mais cultura, enfim da exploração do homem pelo homem, que só na compaixão teria um remédio. Lütkeaus, ao se contrapor aos críticos de esquerda que, como Lukács, viam na filosofia de Schopenhauer, "uma filosofia de rentier que aspirava apenas a 'tranquilidade dos salões' e que expressava como angústia do caos a aliança entre a burguesia e a contra revolução" (idem, p.22), apesar da plausibilidade de fachada que tais acusações apresentam, afirma que este tipo de juízo não pode anular o juízo do próprio Marx, transmitido por Franziska Kugelmann que afirma ter Marx censurado a condenação sumária de Schopenhauer, reconhecendolhe uma "Ética profunda da justiça e compaixão"; mesmo que Lütkeaus suspeite que a expressão usada, ética da justiça e compaixão deva ser atribuída à linguagem da autora e não do próprio Marx, aceita este testemunho "pois Marx efetivamente não encontrou em Schopenhauer nenhum conceito de compaixão destacado da práxis" (idem, pp.22-23).

A moral da compaixão em Schopenhauer, baseada no sentimento que traduz a pertença de todos à mesma essência, liga-se diretamente com a questão da razão. Mais uma vez é contestada a razão kantiana enquanto prática e o fato de razão, a lei moral universal, vista como uma lei meramente formal sem qualquer eficácia para agir contra as inclinações sensíveis humanas, ou seja, sem qualquer aplicação (Schopenhauer, 1995, §4). Schopenhauer, nisto próximo de Hegel, põe em questão a moral do dever ser, que embute o paradoxo de não poder, enquanto puro dever, tornar-se ação moral efetiva (Hegel, 1998, pp.126-27). Para Schopenhauer, se há razão, esta é só teórica, impondo seus ditames através do muss, a razão pura prática seria uma reminiscência da alma rationalis da escolástica. Tudo isso teria a ver com a crítica que ele faz à moral formal e abstrata de Kant não ter efetividade no mundo empírico (Schopenhauer, 1995, §6). 
Outro argumento em apoio à tese de que o pessimismo não é um quietismo vem exposto pelo próprio Horkheimer no texto “Atualidade de Schopenhauer". Schopenhauer, "apesar de queixar-se que a honorável palavra Ilustração tornou-se, na boca da 'filosofia de diversão', uma espécie de xingamento, se empenhava na luta contra a superstição, a intolerância e o dogmatismo racionalista" (Horkheimer, 1986). A filosofia de diversão (Spass philosophie) propriamente dita é para ele a filosofia universitária que tem em vista o ganha-pão, em comparação com o verdadeiro pensamento filosófico que só tem em vista a verdade. [Condenava, no entanto, a busca ilustrada de unificar o que existe hoje ou no futuro mesmo a história sangrenta com aquilo que deve ser]. Embora "ele não tenha justificado filosófica ou teologicamente ou com uma filosofia da História a solidariedade com quem sofre e com os deserdados no mundo", não admite qualquer paz enquanto houver miséria

e fome - "a vida heroica é a que se empenha em lutar com grande empenho e sem recompensa para o bem de todos" (Horkheimer, 1980, p.100; Horkheimer 1986).

Horkheimer, sem desconhecer o ódio de Schopenhauer por Hegel, "não vê tanta distância entre eles" (Horkheimer, 1980, p.100). Pois também na filosofia deste último impera a contradição, o negativo e a dor (idem, ibidem). A contemplação estética e filosófica de Schopenhauer não está tão afastada da doutrina da natureza e do espírito objetivo em Hegel (idem, p.101). Se ele fala da meta final da História e do Espírito Absoluto, a rota real da história é cheia de perecimentos e tristezas que não se devem só à natureza, mas ao querer humano. Mas "Schopenhauer recusa a genial salvação da positividade do Absoluto realizada pelo último sistemático da História da Filosofia". E segundo Horkheimer,

nesta recusa de qualquer falso consolo, Schopenhauer vai além de Hegel, na sua recusa de admitir a consistência de um sistema que abranja o mundo e com isso o desenvolvimento da humanidade até o ponto em que se torne possível tal discernimento filosófico como fundamento para divinizar o ser (idem, ibidem).

Enfim, a crítica à Razão absoluta e ao sistema, que engendra em Hegel a positividade do Absoluto, é antes de tudo o alvo principal de Schopenhauer, o que Horkheimer não chega a dizer textualmente, mas com o que parece concordar. $\mathrm{E}$, neste ponto, o divórcio entre eles é inevitável. A crítica ao sistema visa por fim o “último grande sistemático", estando na crítica ao espírito sistemático de Kant e à razão kantiana, apenas o germe da sua plena realização no hegelianismo.

\section{Referências}

Adorno, T. W., Horkheimer, M. (1985). "Excurso II - Juliette ou Esclarecimento e Moral”. In: Dialética do Esclarecimento: fragmentos filosóficos. Tradução de Guido Antonio de Almeida. Rio de Janeiro, RJ: Jorge Zahar Editor.

Andrade, M. de. (2016 [1928]). Macunaíma - edição comemorativa aos 70 anos da 
morte do escritor. São Paulo, SP: Projeto Livro Livre.

Arantes, P. E. (1996). “O Paradoxo do Intelectual”. In: O ressentimento da dialética: dialética e experiência intelectual em Hegel / Antigos estudos sobre o $A B C$ da miséria alemã. São Paulo, SP: Paz e Terra.

Cacciola, M.L. (1983). Schopenhauer e a Crítica da razão - a razão e as representações abstratas. Revista Discurso, 15, pp.91-106.

Chiarello, M. G. (2004). Das lágrimas das coisas: Estudos sobre o conceito de natureza. Campinas, SP: Ed. Unicamp.

Hegel, G.W.F. (1998), Fenomenologia do Espírito. Tradução de Paulo Meneses. Petrópolis: Ed. Vozes.

Horkheimer, M. (1973). “Meios e fins”. In: Crítica de la razón instrumental. Tradução de H. A. Murena e D. J. Vogelmann. Buenos Aires: Ed. Sur.

. (1980). «Aktualität Schopenhauers». In: Ebeling, H., Lütkeaus, L. (orgs.). Schopenhauer und 'Marx: Philosophie des Elends - Elend der Philosophie?. Königstein: Hain.

(1986). “La actualidad de Schopenhauer". In: Adorno, T.W. Sociologica. Tradução de Victor Sánchez de Zavala. Madrid: Taurus.

. Kant, I. (1900a). «Kritik der reinen Vernunft». In: Kants Werke. Vol. III. Berlin: Akademisches Ausgabe.

. (1900b). «Beantwortung der Frage: Was ist Aufklärung». In: Kants Werke. Vol. VIII. Berlin: Akademisches Ausgabe.

Lütkehaus, L. (2007). Esiste una sinistra schopenhaueriana? Ovvero: il pessimismo è un quietismo? In: Ciracì, F., Fazio, D.M., Pedrocchi, F. (orgs.). Arthur Schopenhauer e la sua scuola (15-34). Lecce: Pensa Multimedia.

Lukács, G. (1975). El assalto a la razón: La trayectoria del irracionalismo desde Schelling hasta Hitler. Tradução de Wenceslao Roces. Barcelona: Ed Grijalbo.

Schopenhauer, A. (1911). "Die Welt als Wille und Vorstellung”. In: Paul Deussen (ed.), Schopenhauer Sämtliche Werke, Vol. 1. München: Piper Verlag.

. (1980a). “O mundo como vontade e representação (III parte)”. Tradução de Wolfgang Leo Maar. In: Maar, W. L., Cacciola, M. L. M. O. Os Pensadores: Schopenhauer (O mundo como vontade de representação, III pt.; Crítica da Filosofia Kantiana; Parerga e Paralipomena, cap. V, VIII, XII, XIV). São Paulo, SP: Abril Cultural.

(1980b). "Crítica da filosofia kantiana" (Apêndice do livro O Mundo como Vontade e Representação). Tradução de Maria Lúcia Cacciola. In: Maar, W. L., Cacciola, M. L. M. O. Os Pensadores: Schopenhauer (O mundo como vontade de representação, III pt.; Crítica da Filosofia Kantiana; Parerga e Paralipomena, cap. V, VIII, XII, XIV). São Paulo, SP: Abril Cultural.

. (1988). Ueber die vierfache wurzel des Satz vom zureichenden Grundes [Quádrupla raiz do princípio de razão suficiente]. Zürich: Haffmans.

(1995). Sobre o Fundamento da Moral. Tradução de Maria Lucia Mello e Oliveira Cacciola. São Paulo, SP: Ed. Martins Fontes. 
- (2003). Fragmentos para a História da Filosofia. Tradução de Maria Lúcia Cacciola. São Paulo, SP: Ed. Iluminuras. (2005a). O mundo como vontade e como representação. Tradução de Jair Barboza. São Paulo, SP: Ed. Unesp.

- (2005b). "Crítica da filosofia kantiana". In: O mundo como vontade e como representação. Tradução de Jair Barboza. São Paulo, SP: Ed. Unesp.

Recebido em: 31.03 .2017

Aceito em: 05.09.2017 